\title{
Letter from the Chief Editor
}

\section{Dr. Dimitrios Papandreou}

Zayed University, Abu Dhabi, UAE

Corresponding Author: Dr.

Dimitrios Papandreou; email: Dim-

itrios.papandreou@zu.ac.ae

Production and Hosting by

Knowledge $\mathrm{E}$

(c) Dr. Dimitrios

Papandreou. This article is distributed under the terms of the Creative Commons

Attribution License, which permits unrestricted use and redistribution provided that the original author and source are credited.

Editor-in-Chief:

Dr. Dimitrios Papandreou

Official Publication of Zayed University, UAE

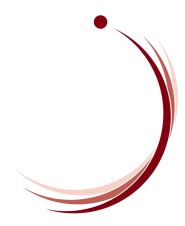

ZAYED UNIVERSITY

\section{S OPEN ACCESS}

Arab Journal of Nutrition and Exercise (AJNE) is a new journal launched in 2015. The focus of AJNE is to provide with updated information on different topics of Nutrition and/or Exercise on all disciplines from all over the world.

The Editorial Board is composed of distinguish faculty members from different Universities around the world. I look forward to working with our editorial team, our reviewers and authors as well as the Zayed University Press, to ensure the continued growth and success of this journal. The AJNE will use the double blind process to review all the incoming articles. The AJNE has no fee charges for publication.

AJNE will receive an ISSN number and be indexed in many well-known databases in the beginning of 2017 (SCOPUS, PubMed and many others).

We look forward to receiving your submissions, and we welcome your ideas and comments for AJNE. 